\section{$\underset{\substack{\text { hommes } \\ \text { \& migrations }}}{ }$}

\section{Hommes \& migrations}

Revue française de référence sur les dynamiques

migratoires

\section{$1321 \mid 2018$}

Les mots de l'exil dans l'Europe du XIXe siècle

\title{
Le voyage de Khadija
}

Film marocain, 2017, de Tarik El Idrissi

\section{Anaïs Vincent}

\section{(2) OpenEdition \\ 1 Journals}

Édition électronique

URL : https://journals.openedition.org/hommesmigrations/4524

DOI : 10.4000/hommesmigrations.4524

ISSN : 2262-3353

Éditeur

Musée national de l'histoire de l'immigration

Édition imprimée

Date de publication : 1 avril 2018

Pagination : 172

ISBN : 978-2-919040-41-4

ISSN : 1142-852X

Référence électronique

Anaïs Vincent, «Le voyage de Khadija », Hommes \& migrations [En ligne], 1321 | 2018, mis en ligne le 01 avril 2018, consulté le 28 juin 2022. URL : http://journals.openedition.org/hommesmigrations/4524 ; DOI : https://doi.org/10.4000/hommesmigrations.4524 


\section{FILMS}



Le voyage

de Khadija

\section{de Tarik El Idrissi}

(Maroc, 2017)

Le troisième documentaire du réalisateur Tarik El Idrissi est né de sa rencontre avec le scénariste maroco-hollandais Abdelkader Benali. On suit Khadijah, une jeune femme néeen Hollande de parents marocains, dans sa quête d'identité, dans sa volonté de comprendre et d'assimiler sa double culture et son héritage familial. Dans l'obscurité apparaît la silhouette d'une jeune femme qui s'entraîne à la boxe. Gros plan sur son visage. Cette ouverture singulière donne le ton. En off, elle se présente et explique sa démarche, ce qui l'a conduit vers cette recherche introspective et son combat pour l'égalité des genres. Enfant, nous raconte-t-elle, elle passait ses étés avec sa famille dans la campagne rifaine, cette région que connait bien le réalisateur, auteur du très remarqué Riff 58-59, briser le silence. À l'adolescence, elle rompt avec son passé et met fin à ces rendez-vous annuels, excédée par les propositions de mariages. Khadijah est une femme émancipée : boxeuse, conductrice du métro d'Amsterdam, motarde. Cette force, elle semble l'avoir hérité de sa grand-mère dont elle a gardé précieusement un portrait photographique.
À la mort de son père, vingt ans plus tard, elle retourne sur les traces de cette femme, véritable légende locale. Les rythmes d'une mélodie arabisante traditionnelle sur des plans de la ville d'Amsterdam en mouvement annoncent son départ. Le réalisateur nous emmène dans une pertinente réflexion sur l'identité, la double culture, la migration et la condition féminine en pays rifain.

On suit avec intérêt et curiosité Khadijah dans son enquête. La caméra et l'équipe de tournage se font discrètes pour enregistrer avec pudeur les émotions des retrouvailles avec ses proches.

La boxe est son lien avec son oncle et le symbole de sa pugnacité. Elle s'entraîne sous le regard perplexe des hommes. Les témoignages se succèdent. Partir sur les traces de cette grand-mère atypique permet d'aborder la question brûlante de la place de la femme dans la société rifaine et, plus largement, dans la société marocaine, et celle de sa propre identité d'immigrée élevée dans une société plus égalitaire. Khadijah va à la rencontre des actrices de la vie locale, comédiennes, intellectuelles, et partage avec elles son histoire, ses réflexions, ses espoirs et ses aspirations féministes.

Tarik El Idrissi porte un regard acéré sur une société sclérosée par des archétypes poussiéreux et relaie le message d'espoir de renouveau porté par ces femmes combatives.

A. V. 